\title{
Morphological evidence of sexual dimorphism in a Continental anole species of south of Mexico
}

\author{
LUIS M. BADILLO-SALDAÑ $A^{1}$, AARON GARCÍA-ROSALES ${ }^{1}$, J. DANIEL LARA-TUFIÑO ${ }^{2}$, \\ AURELIO RAMÍREZ-BAUTISTA ${ }^{1, \vee}$ \\ ${ }^{1}$ Laboratorio de Ecología de Poblaciones, Centro de Investigaciones Biológicas, Instituto de Ciencias Básicas e Ingeniería, Universidad Autónoma del \\ Estado de Hidalgo, Km 4.5 carretera Pachuca-Tulancingo, 42184, Mineral de La Reforma, Hidalgo, México. ^email: ramibautistaa@gmail.com \\ ${ }^{2}$ Laboratorio de Herpetología, Departamento de Biología Evolutiva, Facultad de Ciencias, Universidad Nacional Autónoma de México, Ciudad \\ Universitaria, CDMX., C.P. 04510, México
}

Manuscript received: 24 September 2019. Revision accepted: 28 October 2019.

\begin{abstract}
Badillo-Saldaña LM, García-Rosales A, Lara-Tufiño JD, Ramírez-Bautista A. 2019. Morphological evidence of sexual dimorphism in a Continental anole species of southeastern Mexico. Biodiversitas 20: 3347-3351. Intersexual differences (sexual dimorphism; SD) have been observed in many traits of vertebrate and invertebrate species. These differences evolved as a response to ecological factors, such as the display of morphological and behavioral attributes during reproduction, territorial defense, or differential use of resources. However, some species of lizards do not show high SD, as is the case of some slender small body-sized anoles of the Caribbean Islands. Despite extensive knowledge about SD in island anoles, SD has not been evaluated for most mainland species. Therefore, the goal of this study was to evaluate the SD of a small body-sized species (Anolis unilobatus) throughout its distribution in Mexico, making use of eight morphological characteristics and multivariate analyses. The results showed that snout-vent (SVL) and forearm (FAL) lengths of males are larger than those of females. This could be explained by males being more territorial, so larger size will make them more successful in defending their territory from other males. Therefore, the difference in SVL and FAL between males and females of this species could be related to defense of their territory. The differences observed in morphological structures between males and females could thus support the hypothesis of sexual selection.
\end{abstract}

Keywords: Anolis unilobatus; intersexual differences; small-sized species; tropical environment

\section{INTRODUCTION}

Sexual dimorphism (SD) is defined as the set of intersexual differences in morphology, physiology, and behavior (Slatkin 1984; Mori et al. 2017). In squamate lizards, differences between sexes are observed in snoutvent length (SVL), body mass, length and width of the head, and length of the tibia and femur (Andrews and Stamps 1994; Elstrott and Irschick 2004). These differences have been related to ecological factors; for example: (i) territorial defense, where the largest and most striking males can scare away invaders more quickly and/or attract a greater number of females than smaller and less striking males (sexual selection; Carranza 1994; RamírezBautista and Vitt 1997); (ii) niche divergence, which suggests that the development of different morphological characteristics can allow male and female to feed on prey of different sizes to avoid overlapping alimentary niches (Hierlihy et al. 2013), or exploit different types of microhabitats (Ramírez-Bautista and Benabib 2001; Butler et al. 2007). This being so, evolution of SD could reduce intraspecific competition by favoring the differential use of resources (space and food) between males and females (Butler et al. 2007), and (iii) fecundity, in which larger females can produce larger litters and/or larger offspring (Pincheira-Donoso and Hunt 2015).

In most species of lizards, SD has been observed on SVL, body mass (Fitch 1978), head size and shape, perch height (Ramírez-Bautista and Benabib 2001), growth rate (Hernández-Salinas et al. 2019), mortality (RamírezBautista 1995), and SVL at sexual maturity (Benabib 2009). SD in the genus Anolis has been explained with reference to gular dewlap and other morphologic traits associated with body shape (ecomorphs) in West Island Anolis lizards (Butler et al. 2007; Losos 2009; Johnson and Wade 2010), while SD in mainland Anolis species has mostly been related to SVL, perch use, and diet (Perry 1996; Ramírez-Bautista and Vitt 1997; Ramírez-Bautista and Benabib 2001). Despite this, there is little information about SD in most of the mainland Anolis species; therefore, it is necessary to determine whether SD occurs in other morphological structures beyond previously reported (Márquez et al. 2005; Siliceo-Cantero et al. 2016; Hernández-Salinas et al. 2019). Therefore, the goal of this study is to analyze the SD of a tiny mainland anole species Anolis unilobatus Köhler and Vesely 2010; east pacific and central depression Chiapas clade see Gray et al. 2019 (We will refer as Anolis unilobatus to the populations of the east pacific lineage, but we are aware of these populations belong to an evolutionarily independent lineage to the populations of the west pacific and of central America Gray et al. 2019). For this, we analyzed sexual differences in eight morphological characteristics through multivariate statistics. Anolis unilobatus is a slender, small body-sized, fast growth rate, with a short life expectancy such as many species of small-bodied-sized (Ramírez-Bautista and Vitt 
1997; Hernández-Salinas et al. 2019). This species inhabits tropical forest, occupying tree branch and grass microhabitats (Lee 1980), as well as tree trunks, which has been referred to as a trunk ecomorph (Lee 1980). This species reaches sexual maturity at a size equal to or larger than $35.0 \mathrm{~mm}$ in SVL (Lee 1996). The reproductive season occurs once a year before the rainy season. During the breeding season, males compete with each other to establish themselves in the best territories, in order to gain access to as many females as possible (Lee 1980; 1996). Therefore, competition between males can favor larger and stronger males. In this sense, sexual dimorphism could be supported by the hypothesis of sexual selection.

\section{MATERIAL AND METHODS}

\section{Data collection}

This study was conducted in five localities (Figure 1) along with the distribution of Anolis unilobatus east pacific clade (see Gray et al. 2019). To avoid bias related to ecological or ontogenetic processes, all sites were surveyed in the same season, during April 10-16, 2017. At each locality, whenever possible, the first ten adult lizards observed were collected; however, due to the unequal proportion of sexes, an equitable sample between them was not obtained. For this, we consider as adult individuals those specimens that had a SVL equal to or larger than 35 $\mathrm{mm}$, as reported by Lee (1980). For each location, a sampling day was used and carried out between 09:00 am to $18: 00 \mathrm{pm}$. Snout-vent length and body mass (BM) of each individual was measured immediately after capture using a Mitutoyo digital caliper (model CD-8"CX; \pm 0.05 $\mathrm{mm})$ and a Pesola spring balance $( \pm 0.01 \mathrm{~g})$, respectively. Once collected, individuals were euthanized using a sodium pentobarbital injection, then fixed in $40 \%$ formalin and subsequently stored in $70 \%$ alcohol. All specimens were deposited in the Laboratorio de Ecología de Poblaciones in the Universidad Autónoma del Estado de Hidalgo. Collection was approved by scientific collection permit SGPA/DGVS/04287/16 issued by SEMARNAT. In laboratory, six morphometric variables of the preserved individuals were measured, following the nomenclature of Köhler (2014): groin-underarm length (GUL), arm length (AL), forearm length (FAL), femur length (FL), tibia length (TL), and the sub-digital lamella number on the fourth toe of the hindfoot (NL).

\section{Data analysis}

To eliminate the effect of SVL on weight, groinunderarm, forearm, arm, femur, and tibia lengths, these variables were entered into a multiple regression model using SVL as the independent variable. Sexual dimorphism (SD) was tested through a discriminant analysis using the residual values from the regression analysis, with sex as the grouping variable (Butler et al. 2007). Subsequently, a canonical correlation analysis was performed to objectively and clearly observe differences between sexes (Badii et al. 2007). All analyses were calculated using Statistica 7.0 (StatSoft, Inc., Tulsa, OK, USA).

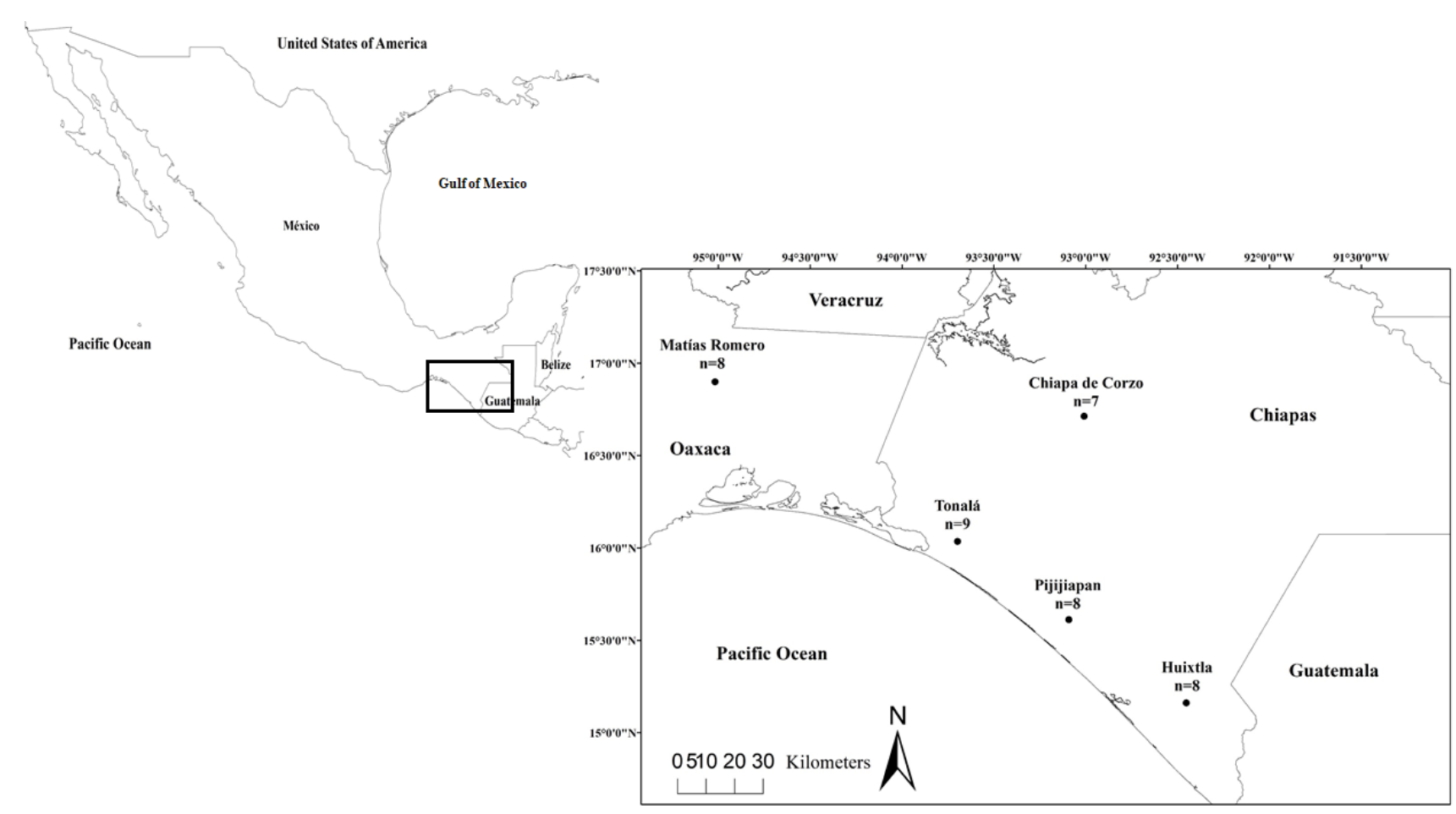

Figure 1. Map of sampling localities in the distribution of Anolis unilobatus. $\mathrm{n}=$ individuals collected at each locality 


\section{RESULTS AND DISCUSSION}

In this study, 44 individuals of Anolis unilobatus were caught at the five localities explored. Eight morphologic characteristics of 17 females and 27 males were measured. The discriminant function analysis showed significant differences between sexes (Wilks $\lambda=0.46, \mathrm{~F}_{8,35}=5.04, \mathrm{P}$ $<0.0003$; Figure 1, Table 1). This result shows that there is $\mathrm{SD}$ in this species, and reinforces evidence of the existence of SD in continental anole species. Differences between sexes were observed in SVL and forearm length (Figure 2; Table 1). These differences were corroborated by a canonical correlation analysis, where it was observed that the differences between sexes were marked: SVL, R = -0.65 ; forearm length, $\mathrm{R}=0.36$ (Figure 3 ). This pattern has been observed in Caribbean anole species, where SD may differ depending on the habitat they exploit (Butler et al. 2000; 2007; Losos 2009). In all other analyzed traits, males showed structures not significantly larger than those of females (Table 1).
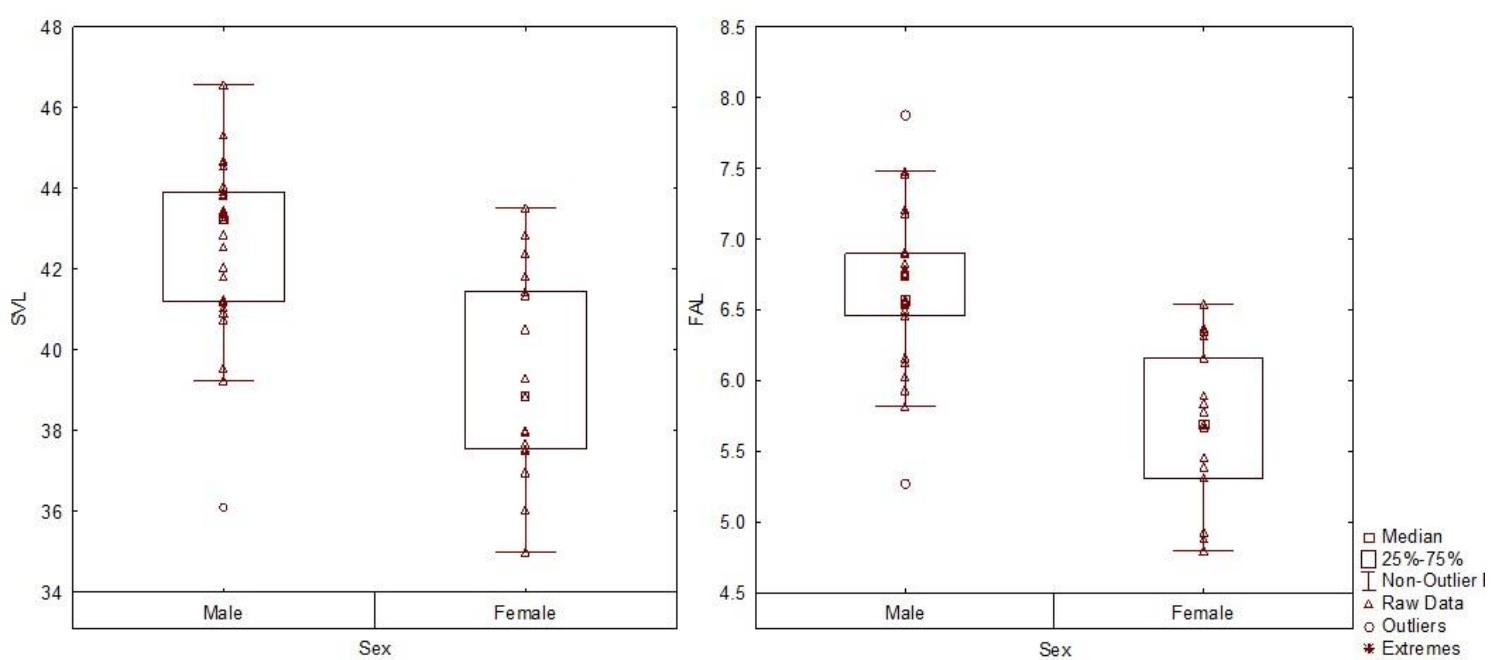

Figure 2. Plot of variability distribution between males and females of Anolis unilobatus. The abbreviations correspond to SVL= snoutvent length; FAL= Forearm length

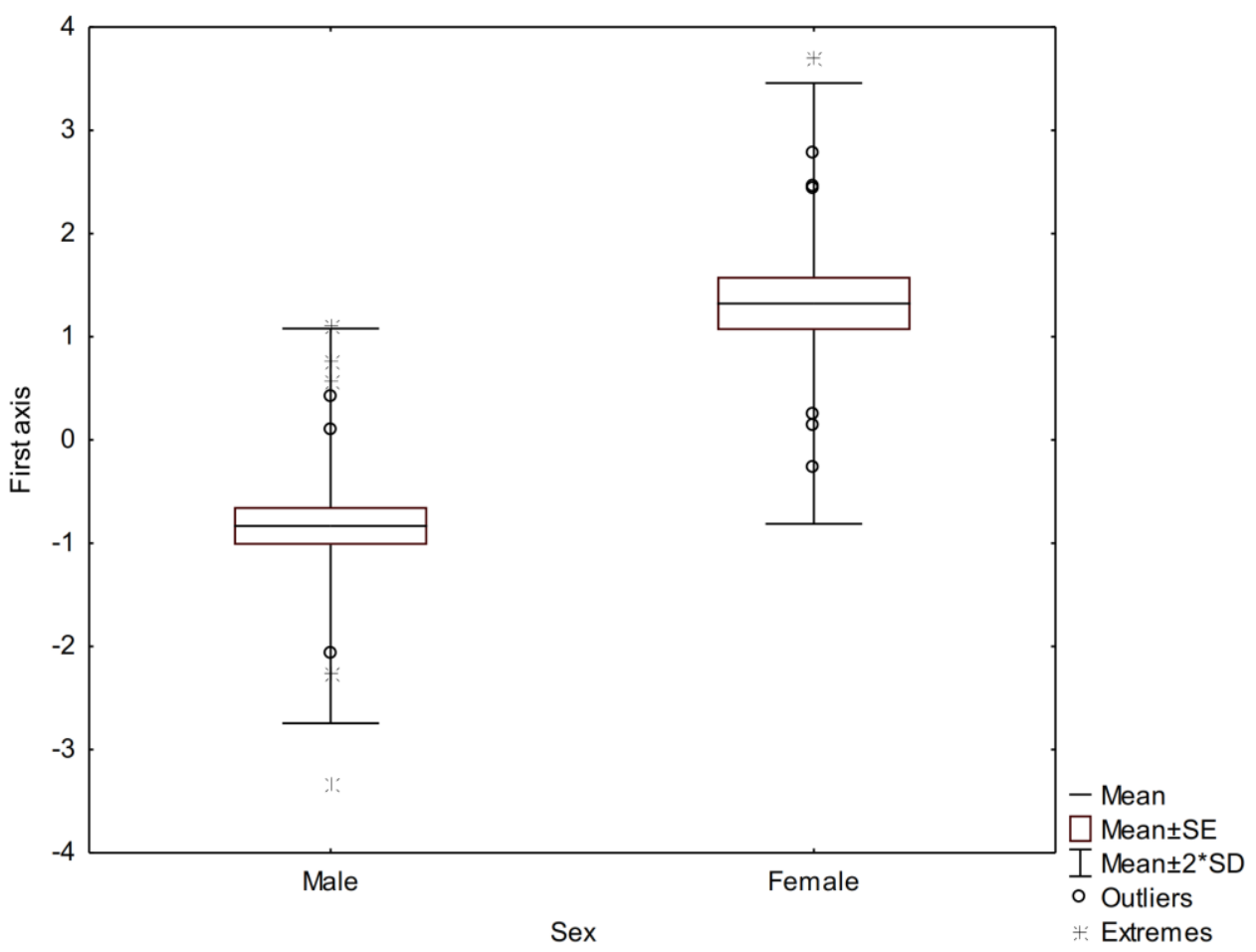

Figure 3. Box plot showing canonical values from discriminant function analysis for males and females. Canonical $\mathrm{R}=0.73$, Wilks $\lambda=$ $0.46, \mathrm{X}^{2}=29.1, \mathrm{P}=0.0002$. Eigenvalue $=1.15$, cumulative variance $=100 \%$. 
Table 1. Descriptive statistics of morphological traits used to evaluate sexual dimorphism of Anolis unilobatus. Morphometric variables are as follows: mean \pm standard deviation (range). Discriminant function analysis values: Wilks $\lambda, F$, significance value $=p$-value. $S V L=$ snout-vent length, $\mathrm{BM}=$ weight, $\mathrm{GUL}=$ groin-underarm length, $\mathrm{AL}=$ arm length, $\mathrm{FAL}=$ forearm length, $\mathrm{FL}=\mathrm{femur}$ length, $\mathrm{TL}=$ tibia length, $\mathrm{NL}=$ sub-digital lamella number on the fourth toe of the hindfoot. All measurements in mm, except weight, which is in grams

\begin{tabular}{llllll}
\hline & Males $(\mathbf{n}=\mathbf{2 7})$ & Females $(\mathbf{n}=\mathbf{1 7})$ & Wilks & F & p-value \\
\hline SVL & $42.90 \pm 2.47(36.1-47.8)$ & $39.34 \pm 2.54(35.0-43.5)$ & 0.80 & 25.14 & $\mathbf{0 . 0 0 0 0 1}$ \\
BM & $1.41 \pm 0.27(0.8-1.8)$ & $1.16 \pm 0.21(0.8-1.5)$ & 0.47 & 0.69 & 0.412 \\
GUL & $17.81 \pm 1.34(14.6-21.2)$ & $17.10 \pm 1.46(14.4-20.3)$ & 0.50 & 2.69 & 0.110 \\
AL & $7.35 \pm 0.61(6.2-8.5)$ & $6.65 \pm 0.37(5.7-7.1)$ & 0.47 & 0.16 & 0.693 \\
FAL & $6.70 \pm 0.59(5.8-7.9)$ & $5.69 \pm 0.54(4.8-6.5)$ & 0.52 & 4.34 & $\mathbf{0 . 0 4 5}$ \\
FL & $9.69 \pm 0.93(7.6-11.6)$ & $9.0 \pm 0.59(8.3-10.5)$ & 0.48 & 1.28 & 0.266 \\
TL & $9.96 \pm 1.07(6.7-11.8)$ & $8.82 \pm 0.72(7.9-10.6)$ & 0.47 & 0.06 & 0.814 \\
NL & $23.56 \pm 1.52(21.0-27.0)$ & $22.88 \pm 1.69(21.0-27.0)$ & 0.46 & 0.01 & 0.927 \\
\hline
\end{tabular}

Generally, sexual dimorphism has historically been related to body size differences in reptiles (Fitch 1978; Cox et al. 2007; Michael et al. 2014; Valencia-Limón et al. 2014; Ramírez-Bautista et al. 2015; 2016). These studies showed that larger lizard and crocodile males have an advantage in territorial defense battles (Cox et al. 2007), since larger, heavier males and/or those with larger jaws have more strength, endurance, and ability to defend their territory successfully than smaller males (Andersson 1994; Herrel et al. 2007; McEvoy et al. 2013). Therefore, a larger male is capable of maintaining a larger territory, which can provide access to more females during the reproductive season (Butler et al. 2000). In this study, A. unilobatus males are larger in SVL than females. This result agrees with other studies that also found Anolis males to be larger than females (Butler et al. 2000; Marquez et al. 2005). Therefore, SD observed in A. unilobatus could be explained by sexual selection (Butler et al. 2000). However, we have not observed differences in other morphological structures, such as head length (male $=11.2$ \pm 0.6 ; female $=10.8 \pm 0.6$ ) and width (male $=6.2 \pm 0.4$; female $=5.9 \pm 0.3$ ). This could be due to the sample size or because the males of this species avoid physical fighting; however, it should be corroborated in subsequent studies.

In the genus Anolis, differences in foreleg length between males and females have been shown to be related to the number of androgen receptors present in each sex (Johnson et al. 2018). These receptors are correlated with the number of push-ups that a male can perform (Foster and Higham 2014), which is associated with territorial defense and courtship displays (Losos 2009). Based on the above, the difference in the length of the forearm observed between males and females of A. unilobatus could be because this species shows matting displays beyond simple use of the gular dewlap, since a defensive or attractive body deployment with greater push-ups intensity and quantity could induce greater reproductive success, as occurs in other anole species (Losos et al. 1993). However, although so far there are no studies that evaluate the number of androgen receptors, nor the relationship between the number, frequency and intensity of push-ups in sexual selection for this species, there are studies conducted in other species of the genus Anolis where it is observed that the difference in the number of push-ups among males of different ages has repercussions on the number of females attracted to them (Losos 2000; 2009).

On the other hand, although we do not evaluate ecological aspects, the sexual dimorphism observed in this study could be explained from the point of view of intraspecific divergence of the ecological niche (Berns 2013; Hierlihy et al. 2013). However, it would be difficult to test this hypothesis, since few studies have demonstrated this relationship reliably (Berns 2013). For example, Márquez et al. (2005), Siliceo-Cantero et al. (2016) and Hernández-Salinas et al. (2019), observed that differences in growth rates and head size between the sexes in $A$. aquaticus and A. nebulosos allow them to feed on different types of prey during their development. Butler et al. (2000) noted that the sexual dimorphism recorded in Anolis species of the Greater Antilles was correlated with the type of microhabitat and perch height that males and females use. Therefore, natural selection and not sexual selection could be the force responsible for maintaining morphological differences between sexes in these species. However, it is necessary to carry out an ontogenetic followup on A. unilobatus to determine whether age at sexual maturity could modify our results, since we took measurements only during a single spring pre-mating season.

In conclusion, this study showed that A. unilobatus present SD in SVL and forearm length. The SD was malebiased, as expected. A comprehensive understanding of sexual dimorphism is complicated because the morphological, ecological and behavioral differences between males and females can be the result of a process of sexual selection, natural selection or an interaction between the two (Berns 2013). Since selection pressure, which promotes $\mathrm{SD}$, can be both natural and sexual, both factors can act together to mold the dimorphic traits of lizard species. In this sense, the presence of sexual dimorphism of A. unilobatus may also be associated with geographical and environmental conditions, for example, the environmental transition that occurs in the mountainous regions of central Chiapas, could lead to morphological variations among populations (Lee 1980; Gray et al. 2019). Therefore, future studies on SD of this species should consider including the dynamic interaction between sexual dimorphism and the environmental, spatial and temporal conditions that 
dominate the area of distribution, since these conditions may alter sexual dimorphism within and among populations, as have been documented in other lizard species (Ramírez-Bautista et al. 2014; 2016). Finally, a comprehensive understanding of sexual dimorphism could be achieved by studying different populations and years, as well as diet, habitat and microhabitat use, behavior, and physiology, with the purpose of generating more robust conclusions about the magnitude of the forces that are shaping sexual dimorphism (Butler et al. 2007).

\section{ACKNOWLEDGEMENTS}

We thank A. Hernández-Melo for his help in the field and M. Schroeder for conducting the English language revision. This study is part of the Ph.D. research of the senior author (LMBS), in the program Biodiversidad $y$ Conservación at the Universidad Autónoma del Estado de Hidalgo, México. A doctoral scholarship was granted to LMBS (Number 591364) by CONACyT. We also thank Anisa Septiasari and an anonymous reviewer for their insightful comments on the manuscript.

\section{REFERENCES}

Andersson MB. 1994. Sexual Selection. Princeton University Press, New Jersey.

Andrews RM, Stamps JA. 1994. Temporal variation in sexual size dimorphism of Anolis limifrons in Panama. Copeia 1994: 613-622.

Badii MH, Castillo J, Cortez K, Wong A, Villalpando P. 2007. Análisis de correlación canónica (ACC) e investigación científica. Innovaciones de negocios 4 (2): 405-422. [Spanish]

Benabib M. 2009. Los vertebrados y las historias de vida. In: Morrone JJ, Magaña P (eds.). Evolución Biologica. Universidad Autónoma de México, Mexico.

Berns CM. 2013. The evolution of sexual dimorphism: understanding mechanisms of sexual shape differences. In Sexual dimorphism. IntechOpen, Rijeka, Croatia.

Butler MA, Sawyer SA, Losos JB. 2007. Sexual dimorphism and adaptive radiation in Anolis lizards. Nature 447:202205.

Butler MA, Schoener TW, Losos JB. 2000. The relationship between sexual size dimorphism and habitat use in Greater Antillean Anolis lizards. Evolution 54 (1): 259-272.

Carranza Almansa JF. 1994. Sistemas de apareamiento y selección sexual. Etología: introducción a la ciencia del comportamiento. Servicio de Publicaciones, Universidad de Extremadura, Espana. [Spanish]

Cox RM, Butler MA, John-Alder HB. 2007. The evolution of sexual size dimorphism in reptiles. In: Fairbairn DJ, Blanckenhorn WU, Székely T. (eds.). Sex, Size and Gender Roles: Evolutionary Studies of Sexual Size Dimorphism. Oxford University Press, Oxford.

Elstrott J, Irschick DJ. 2004. Evolutionary correlations among morphology, habitat use and clinging performance in Caribbean Anolis lizards. Biol J Linn Soc 83 (3): 389-398.

Fitch HS. 1978. Sexual size differences in the genus Sceloporus. Univ Kansas Mus Nat Hist 51: 441-461.

Foster KL, Higham TE. 2014. Context-dependent change in motor control and kinematics during locomotion: modulation and decoupling. Proc R Soc B Biol Sci 281 (1782): 20133331. DOI: 10.1098/rspb.2013.3331.

Gray LN, Barley AJ, Poe S, Thomson RC, Nieto-Montes de Oca A, Wang IJ. 2019. Phylogeography of a widespread lizard complex reflects patterns of both geographic and ecological isolation. Mol Ecol 28 (3): 644-657.

Hernández-Salinas U, Ramírez-Bautista A, Cruz-Elizalde R, Meiri S, Berriozabal-Islas C. 2019. Ecology of the growth of Anolis nebulosus (Squamata: Dactyloidae) in a seasonal tropical environment in the Chamela region, Jalisco, Mexico. Ecol Evol 9 (4): 2061-2071.
Herrel A, McBrayer LD, Larson PM. 2007. Functional basis for sexual differences in bite force in the lizard Anolis carolinensis. Biol J Linn Soc 91 (1): 111-119.

Hierlihy CA, García-Collazo R, Chavez-Tapia CB, Mallory FF. 2013. Sexual dimorphism in the lizard Sceloporus siniferus: support for the intraspecific niche divergence and sexual selection hypotheses. Salamandra 49: 1-6.

Johnson MA, Kricher BK, Castro DJ. 2018. The evolution of androgen receptor expression and behavior in Anolis lizard forelimb muscles. J Compar Physiol Anim 204: 71-79.

Johnson MA, Wade J. 2012. Behavioral display systems across nine Anolis lizard species: sexual dimorphisms in structure and function. Proc R Soc B Biol Sci 277: 1711-1719.

Köhler G. 2014. Characters of external morphology used in Anolis taxonomy: Definition of terms, advice on usage, and illustrated examples. Zootaxa 3774: 201-257.

Lee JC. 1980. Variation and systematics of Anolis sericeus complex (Sauria: Iguanidae). Copeia 1980 (2): 310-320.

Lee JC. 1996. The Amphibians and Reptiles of the Yucatán Peninsula. Cornell University Press, USA.

Losos JB. 2009. Lizards in an evolutionary tree: ecology and adaptive radiation of anoles. University of California Press, Berkely, CA.

Losos JB, Creer DA, Glossip D, Goellner R, Hampton A, Roberts G, Haskell N, Taylor P, Ettling J. 2000. Evolutionary implications of phenotypic plasticity in the hindlimbs of the lizard Anolis sagrei. Evolution 54 (1): 301-305.

Losos JB, Marks JC, Schoener TW. 1993. Habitat use and ecological interactions of an introduced and a native species of Anolis lizard on Grand Cayman. Oecologia 95: 525-532.

Márquez C, Mora JM, Bolaños F, Rea S. 2005. Aspectos de la biología poblacional en el campo de Anolis aquaticus, Sauria: Polychridae en Costa Rica. Ecología Aplicada 4 (1-2): 59-69.

McEvoy J, While GM, Sinn DL, Wapstra E. 2013. The role of size and aggression in intrasexual male competition in a social lizard species, Egernia whitii. Behav Ecol Sociobiol 67 (1): 79-90.

Michael DR, Banks SC, Piggott MP, Cunningham RB, Crane M, MacGregor C, McBurney L, Lindenmayer DB. 2014. Geographical variation in body size and sexual size dimorphism in an Australian lizard, Boulenger's skink (Morethia boulengeri). PloS One 9 (10): e109830. DOI: 10.1371/journal.pone.0109830.

Mori E, Mazza G, Lovari S. 2017. Sexual dimorphism. In: Vonk J, Shakelford T (eds.). Encyclopedia of Animal Cognition and Behavior. Springer International Publishing, Switzerland.

Perry G. 1996. The evolution of sexual dimorphism in the lizard Anolis polylepis (Iguania): evidence from intraspecific variation in foraging behavior and diet. Canadian J Zool 74:1238-1245.

Pincheira-Donoso D, Hunt J. 2015. Fecundity selection theory: concepts and evidence. Biol Rev Camb Philos Soc 92 (1): 341-356.

Ramírez-Bautista A. 1995. Demografía y reproducción de la lagartija arborícola Anolis nebulosus de la región de Chamela, Jalisco. [Dissertation]. Facultad de Ciencias, Universidad Nacional Autónoma de México. [Spanish]

Ramírez-Bautista A, Benabib M. 2001. Perch height of the arboreal lizard Anolis nebulosus (Sauria: Polichrotidae) from a tropical dry forest of Mexico: effect of the reproductive season. Copeia 2001: 187-193.

Ramírez-Bautista A, Hernández-Salinas U, Cruz-Elizalde R, Lozano A, Rodríguez-Romero FDJ. 2016. Sexual dimorphism and reproductive traits over time in Sceloporus aeneus (Squamata: Phrynosomatidae), based on a population in the Transmexican Volcanic Belt, Mexico. Salamandra 52: 197-203.

Ramírez-Bautista A, Luría-Manzano R, Cruz-Elizalde R, Pavón NP, Wilson DL. 2015. Variation in reproduction and sexual dimorphism in the long-tailed spiny lizard, Sceloporus siniferus, from the southern Pacific coast of Mexico. Salamandra 51 (2): 73-82.

Ramírez-Bautista A, Vitt LJ. 1997. Reproduction in the lizard Anolis nebulosus (Polychrotidae) from the Pacific coast of Mexico. Herpetologica 53: 423-431.

Siliceo-Cantero HH, García A, Graham-Reynolds R, Pacheco G, Lister BC. 2016. Dimorphism and divergence in island and mainland Anoles. Biol J Linn Soc 118: 852-872.

Slatkin M. 1984. Ecological causes of sexual dimorphism. Evolution 38 (3): 622-630.

Valencia-Limón ER, Castro-Franco R, Bustos-Zagal MG. 2014. Dimorfismo sexual y ciclo reproductor de Sceloporus horridus horridus (Wiegmann 1939) (Sauria: Phrynosomatidae). Acta Zoológica Mexicana 30 (1): 91-105. 